Research Article

\title{
Removal of Acid Red 88 Using Activated Carbon Produced from Pomelo Peels by KOH Activation: Orthogonal Experiment, Isotherm, and Kinetic Studies
}

\author{
Zheng Liu $\mathbb{D}$ and Konglong Xing \\ School of Environmental Science and Engineering, Xiamen University of Technology, Xiamen, China \\ Correspondence should be addressed to Zheng Liu; liuzh@xmut.edu.cn
}

Received 4 December 2020; Revised 25 December 2020; Accepted 5 January 2021; Published 16 January 2021

Academic Editor: Rabia Rehman

Copyright (c) 2021 Zheng Liu and Konglong Xing. This is an open access article distributed under the Creative Commons Attribution License, which permits unrestricted use, distribution, and reproduction in any medium, provided the original work is properly cited.

\begin{abstract}
Activated carbon (PPAC) from pomelo peels was prepared by carbonization and $\mathrm{KOH}$ activation. The performance of PPAC was assessed by removing acid red 88 (AR88) in aqueous solution. The most suitable activation processes were found by orthogonal experiments, aimed to achieve the maximum of removal capacity of AR88. Moreover, the possible mechanisms of adsorption were studied through the results of characterization, isotherm fitting, and kinetics simulation. Results showed the preparation parameter that mattered the most to AR88 removal efficiency was the activation temperature of PPAC, followed by impregnation ratio and activation time. The optimal preparation conditions of PPAC were at activation temperature $800^{\circ} \mathrm{C}$, activation time $90 \mathrm{~min}$, and impregnation ratio $2.5: 1$. The characterization results showed optimal PPAC had a microporous and amorphous carbon structure whose BET specific area and total pore volume were $2504 \mathrm{~m}^{2} / \mathrm{g}$ and $1.185 \mathrm{~cm}^{3} / \mathrm{g}$, respectively. The isotherm fitting demonstrated that the sorption process followed the Langmuir model, and theoretical maximal sorption value was $1486 \mathrm{mg} / \mathrm{g}$. The kinetics simulation showed that the pseudo-second-order model described the sorption behavior better, suggesting chemisorption seemed to be the rate-limiting step in the adsorption process. This work presented that PPAC was a promising and efficient adsorbent for AR88 from water.
\end{abstract}

\section{Introduction}

Dyes are important materials in paper, textile, leather, and other industries. After a dying process, a large amount of dye wastewater are generated and released into the environment. It is reported that approximately 1.6 million tons of dyes were produced annually [1]. Unfortunately, about $12 \%$ of synthetic dyes are lost during manufacturing and processing, and approximately $20 \%$ of them enter industrial wastewater [2]. Dye wastewater seriously threatened the ecological system and human health because many of the dye wastewater are difficult to treat and are very venenous or strongly oncogenic [3-5]. Therefore, dyes must be removed during sewage discharge. As a common azo dye, acid red 88 (AR88, $\mathrm{C}_{20} \mathrm{H}_{13} \mathrm{NaN}_{2} \mathrm{O}_{4} \mathrm{~S}$ ) is mainly used for dyeing wool, silk, and nylon fabrics. AR88 is difficult to be degraded, and its biotransformed products are carcinogenic to humans [6].
Thus, it is of interest to take effective measures to treat dyecontaining wastewater.

Many removal methods have been reported, such as advanced oxidation process [7-9], membrane filtration [10], ion exchange [11], electrochemical process [12, 13], biological treatment process [14], and adsorption [15, 16]. However, only few are accepted by industries. Adsorption is still viewed as the most economical and simplest process [17, 18]. Activated carbon (AC) is the most popular commercial adsorbent due to its rich raw materials, perfect adsorption capacity, and easy processability. Current studies usually focus on using biomass and other low-cost materials as precursors, such as coconut shells $[19,20]$, palm shells $[21,22]$, rice husks $[23,24]$, date stones $[25,26]$, and walnut shells $[27,28]$.

Pomelo (Citrus maxima) is a widely cultivated Rutaceae arbor in South China and Southeast Asia. China is a large pomelo producer, and approximately $4.8 \times 10^{6}$ tons of 
pomelos were harvested in 2017 , indicating $1.49 \times 10^{6}$ tons of pomelo peels were generated. However, most of the pomelo peels were thrown away, giving rise to wasting resources and potential contamination.

Previous reports found that pomelo peel is an attractive adsorbent precursor for adsorbing heavy metals [29], antibiotics [30, 31], and organic pollutants [32, 33]. In the interest of sustainability, this study selected pomelo peels to prepared AC (PPAC) for removing AR88. Potassium hydroxide $(\mathrm{KOH})$ was used as a chemical activator. The influences of significant preparation parameters (activation temperature, activation time, and impregnation ratio) on AR88 removal were discussed by an orthogonal experiment. The possible mechanisms of adsorption were studied through the analysis of characterization (SEM, XRD, and BET), isotherm fitting (Langmuir, Freundlich, and Temkin), and kinetics simulation (pseudo-first-order model, pseudosecond-order model, and intraparticle diffusion model).

\section{Materials and Methods}

2.1. Materials and Regents. Pomelo peels collected from a local fruit shop were the raw material. The raw precursor was first dried in the sun naturally and followed by drying in an oven at $110^{\circ} \mathrm{C}$ for $48 \mathrm{~h}$. Then, they were smashed with a grinder and passed through a sieve to get a particle size range of 80-200 CHN mesh in advance of the following experiment. Figure 1 shows the pomelo peels, pomelo peels meal, and carbonized pomelo peels. All chemicals used were of analytical grade. Distilled water was used for preparation of solutions. AR88 was chosen for adsorbate, and its structure is shown in Figure 2.

2.2. Adsorbent. The preparation of PPAC primarily consisted of carbonization and activation. The brief preparation processes are illustrated in Figure 3. In brief, the dried precursor was put in a tubular stove for pyrolysis with $\mathrm{N}_{2}$ flow at $600^{\circ} \mathrm{C}$ for $2 \mathrm{~h}$. Then, the carbonized material was impregnated with $\mathrm{KOH}$ at different mass ratios $(1: 1-2.5: 1$, chemical: sample), and the mixture was subjected to activation at different activation temperatures $\left(650-800^{\circ} \mathrm{C}\right)$ for different activation times (90-180 $\mathrm{min})$. After reaction, the resultant activated carbon (PPAC) was repeatedly rinsed with $0.1 \mathrm{M} \mathrm{HCl}$ solution and hot deionized water to remove superfluous alkali. Afterwards, PPAC was dried in an oven at $110^{\circ} \mathrm{C}$ for $24 \mathrm{~h}$. Finally, PPAC was sieved into $80-200 \mathrm{CHN}$ mesh powder for further experiments.

The effect of activation conditions on adsorption efficiency of PPAC was evaluated on the basis of the amount of AR88 adsorbed at equilibrium $q_{e}(\mathrm{mg} / \mathrm{g})$, which was figured out by the following equation:

$$
q_{e}=\frac{\left(C_{0}-C_{e}\right) \times V}{W}
$$

where $C_{0}$ and $C_{e}(\mathrm{mg} / \mathrm{l})$ are the solution concentrations of AR88 at initial and at equilibrium, respectively; $V(\mathrm{l})$ is the volume of AR88 solution; and $W(\mathrm{~g})$ is the mass of PPAC.
For the adsorption experiments, the procedures were conducted as follows: $0.1000 \mathrm{~g}$ PPAC was added to $300 \mathrm{ml}$ of prepared AR88 solution without $\mathrm{pH}$ adjustment. The mixed suspension was stirred in a rotary shaker $\left(25^{\circ} \mathrm{C}, 180 \mathrm{r} / \mathrm{min}\right)$. After reaction, the mixed suspension was filtered by $0.45 \mu \mathrm{m}$ filtering membrane. The concentration of AR88 in solution was analyzed by an UV-Vis spectrophotometer (UV-2450, Shimadzu) at the wavelength of $503 \mathrm{~nm}$. Each experiment was replicated, and average value was adopted in analysis.

2.3. Characterization of PPAC. The SEM micrographs were analyzed using a scanning electron microscope (FEI Inspect F50). The X-ray diffraction (XRD) patterns of PPACs were recorded by an X-ray diffraction analyzer (Bruker D8 ADVANCE). Cu/ $\mathrm{K} \alpha$ radiation was used, and the scan speed was $4^{\circ} / \mathrm{min}$, operating at $40 \mathrm{kV}$ and $30 \mathrm{~mA}$. The textural characterization was manifested by $\mathrm{N}_{2}$ adsorption-desorption at $-196^{\circ} \mathrm{C}$ using an automated surface area and porosity analyzer (TriStar II 3020).

2.4. Orthogonal Experiment. The orthogonal experiment was conducted to investigate the influence of preparation conditions on the dye removal. The levels of preparation conditions are illustrated in Table 1. The initial concentrations of AR88 solution were $500 \mathrm{mg} / \mathrm{l}$. The aqueous samples for analysis were taken at equilibrium.

2.5. Adsorption Isotherms. The adsorption mechanism can be partly deciphered via adsorption isotherm models. The initial concentrations of AR88 solution in isothermal adsorption experiments were 200, 300, 400, 500, and $600 \mathrm{mg} / \mathrm{l}$. The adsorbents used were PPAC of Run 13 in the orthogonal experiment. The aqueous samples for analysis were taken at equilibrium. In this work, the isothermal experiment data were fitted using Langmuir, Freundlich, and Temkin isotherm models given by the following equations, respectively:

$$
\begin{aligned}
& \text { Langmuir isotherm: } \frac{C_{e}}{q_{e}}=\frac{1}{q_{m} K_{L}}+\frac{1}{q_{m}} C_{e}, \\
& \text { Freundlich isotherm: } \ln q_{e}=\ln K_{F}+\frac{1}{n} \ln C_{e} \text {, } \\
& \text { Temkin isotherm: } q_{e}=B \ln K_{T}+B \ln C_{e},
\end{aligned}
$$

where $q_{m}(\mathrm{mg} / \mathrm{g})$ presents the theoretical maximal sorption value, $K_{L}(1 / \mathrm{mg})$ presents the Langmuir coefficient, $K_{F}$ $\left((\mathrm{mg} / \mathrm{g}) \times(\mathrm{l} / \mathrm{mg})^{1 / n}\right)$ and $n$ are the Freundlich coefficients, and $B$ and $K_{T}(1 / \mathrm{mg})$ are the Temkin coefficients.

2.6. Adsorption Kinetics. The adsorption kinetics was used to study the adsorption rate and the latent rate-limiting steps. The initial concentrations of AR88 solution in kinetics adsorption experiments were 200, 400, and $600 \mathrm{mg} / \mathrm{l}$. The adsorbents used were PPAC of Run 13 of the orthogonal experiment. The concentrations of AR88 solution were analyzed at presupposed time intervals. The adsorbing capacity at time $t, q_{\mathrm{t}}(\mathrm{mg} / \mathrm{g})$, is given as follows: 


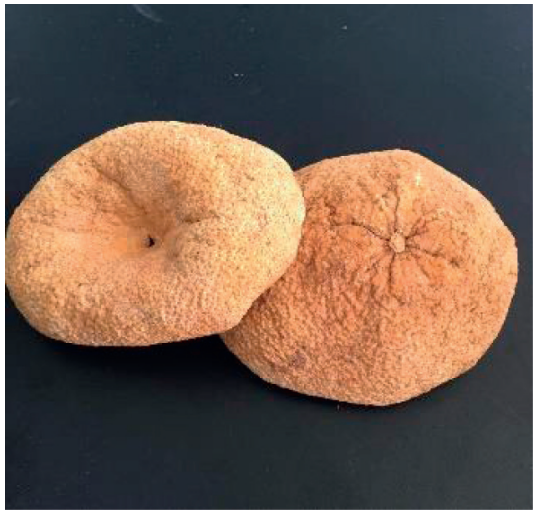

(a)

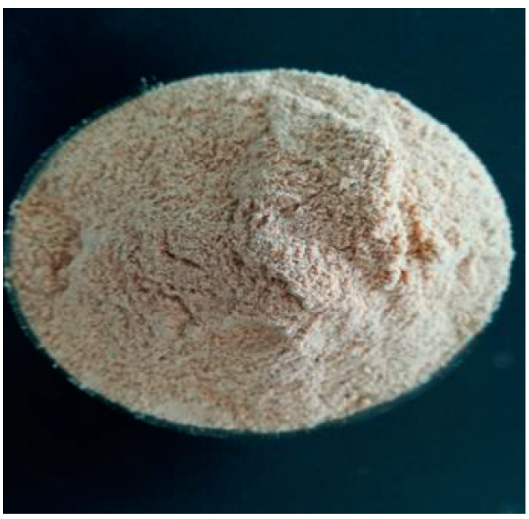

(b)

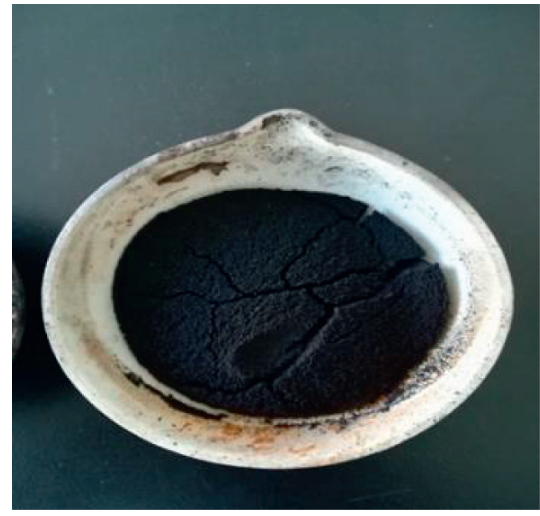

(c)

Figure 1: Pomelo peels (a), pomelo peels meal (b), and PPAC (c).<smiles>O=S(=O)(O)c1ccc(N=Nc2c(O)ccc3ccccc23)c2ccccc12</smiles>

FIGURE 2: The 2D structure of AR88.

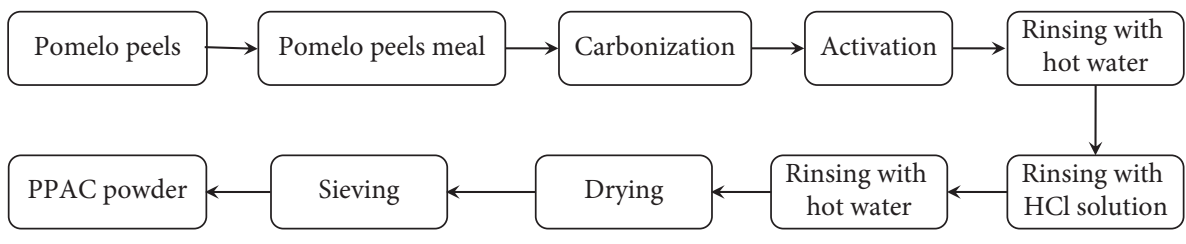

Figure 3: Brief preparation process of PPAC.

TABLE 1: Levels of parameters in an orthogonal experiment.

\begin{tabular}{lccc}
\hline Levels & & Parameters & \\
& Activation temperature A $\left({ }^{\circ} \mathrm{C}\right)$ & Activation time B (min) & Impregnation ratio C \\
\hline Level 1 & 650 & 90 & $1.0: 1$ \\
Level 2 & 700 & 120 & $1.5: 1$ \\
Level 3 & 750 & 150 & $2.0: 1$ \\
Level 4 & 800 & 180 & $2.5: 1$ \\
\hline
\end{tabular}

$$
q_{t}=\frac{\left(C_{0}-C_{t}\right) \times V}{W}
$$

where $C_{t}(\mathrm{mg} / \mathrm{l})$ is the concentration of AR88 in solutions at time $t$ ( $\mathrm{min})$. The kinetics data were simulated by the pseudo-first-order model, pseudo-second-order model, and intraparticle diffusion model listed as follows, respectively:
Pseudo - first - order model: $\ln \left(q_{e}-q_{t}\right)=\ln q_{e}-k_{1} t$,

Pseudo - second - order model: $\frac{t}{q_{t}}=\frac{1}{k_{2} q_{e}^{2}}+\frac{t}{q_{e}}$ 
Intraparticle diffusion model : $q_{t}=k_{3} t^{0.5}+C$,

where $q_{e}$ and $q_{t}(\mathrm{mg} / \mathrm{g})$ have been defined in equations (1) and $(5) ; k_{1}(1 / \mathrm{min}), k_{2}(\mathrm{~g} /(\mathrm{mg} \cdot \mathrm{min}))$, and $k_{3}\left(\mathrm{mg} /\left(\mathrm{g} \cdot \mathrm{min}^{1 / 2}\right)\right)$ are the adsorption rate constants; and $C(\mathrm{mg} / \mathrm{g})$ is the constant of the intraparticle diffusion model.

\section{Results and Discussion}

3.1. Orthogonal Experiment. Table 2 illustrates the results of the orthogonal experiment. It was seen that the AR88 adsorption varied from $379.21 \mathrm{mg} / \mathrm{g}$ to $1473.59 \mathrm{mg} / \mathrm{g}$. The range analysis was easy to show the influence of preparation parameters on AR88 adsorption. The average value of the experiment index was defined as $k_{i}(i=1,2,3,4)$, and the range is denoted by $R$ in Table 3 . Higher $k_{\mathrm{i}}$ showed a bigger influence. Based on the range values $R_{A}>R_{C}>R_{B}$, it indicated that the influence degree of the preparation conditions on AR88 adsorption was activation temperature $>$ impregnation ratio $>$ activation time. Meanwhile, since the $k_{i}$ was the highest at the combination $\mathrm{A}_{4} \mathrm{~B}_{1} \mathrm{C}_{4}$, the best levels for AR88 adsorption are listed as follows: activation temperature was $800^{\circ} \mathrm{C}$, activation time was $90 \mathrm{~min}$, and impregnation ratio was $2.5: 1$.

Figure 4 intuitively shows the influence of preparation conditions on AR88 adsorption. It presented that as the activation temperature raised from $650^{\circ} \mathrm{C}$ to $800^{\circ} \mathrm{C}$, AR88 adsorption value increased. This might be because higher temperature was beneficial to higher reaction rate and the generation of more new pores. During the preparation, the development of porosity was followed by the reduction reactions as follows [34]:

$6 \mathrm{KOH}+2 \mathrm{C} \longrightarrow 2 \mathrm{~K}+3 \mathrm{H}_{2}+2 \mathrm{~K}_{2} \mathrm{CO}_{3}$

$\mathrm{KOH}+\mathrm{C} \longrightarrow \mathrm{K}+1 / 2 \mathrm{H}_{2}+\mathrm{CO}$

The boiling point of element potassium is $770^{\circ} \mathrm{C}$. At $800^{\circ} \mathrm{C}$, the generated metallic potassium gas diffused into the internal structure of the char, expanding formed pores and producing fresh pores. These further pores offered more tunnels for dye molecules to enter the porosities [35].

From Figure 4, it was also observed AR88 adsorption declined with increasing activation time. With a longer time, the carbon atoms on the skeleton could be burned, and some of original micropores enlarged and developed into mesopores. These caused the elimination of pore areas and volumes, which was futile for AR88 adsorption [36].

Figure 4 also exhibits that AR88 adsorption raised as the impregnation ratio increased. This might be because a small impregnation ratio meant less of activating agent, which induced insufficient contact between $\mathrm{KOH}$ and carbon from pomelo peels. Thus, incomplete activation led to limited generation of pores. As the impregnation ratio increased, sufficient activation improved the development of porosity, which was favorable for the adsorption.

3.2. Activated Carbon Characterization. Figure 5 shows the SEM micrographs of pomelo peel, carbonized pomelo peel, and PPAC $\left(\mathrm{A}_{4} \mathrm{~B}_{1} \mathrm{C}_{4}\right)$. As shown in Figures 5(a) and 5(b), the morphology of pomelo peel was a smooth surface but with a
TABLE 2: Results of the orthogonal experiment.

\begin{tabular}{lcccc}
\hline Runs & A & B & C & AR88 adsorption $(\mathrm{mg} / \mathrm{g})$ \\
\hline 1 & 650 & 90 & $1.0: 1$ & 379.21 \\
2 & 650 & 120 & $1.5: 1$ & 438.21 \\
3 & 650 & 150 & $2.0: 1$ & 451.74 \\
4 & 650 & 180 & $2.5: 1$ & 498.93 \\
5 & 700 & 90 & $1.5: 1$ & 454.88 \\
6 & 700 & 120 & $2.0: 1$ & 695.09 \\
7 & 700 & 150 & $2.5: 1$ & 706.37 \\
8 & 700 & 180 & $1.0: 1$ & 639.03 \\
9 & 750 & 90 & $2.0: 1$ & 923.49 \\
10 & 750 & 120 & $2.5: 1$ & 978.40 \\
11 & 750 & 150 & $1.0: 1$ & 732.67 \\
12 & 750 & 180 & $1.5: 1$ & 857.03 \\
13 & 800 & 90 & $2.5: 1$ & 1473.59 \\
14 & 800 & 120 & $1.0: 1$ & 720.40 \\
15 & 800 & 150 & $1.5: 1$ & 765.39 \\
16 & 800 & 180 & $2.0: 1$ & 575.22 \\
\hline
\end{tabular}

TABLE 3: Range analysis of the orthogonal experiment.

\begin{tabular}{lcccc}
\hline Levels & $\mathrm{A}$ & $\mathrm{B}$ & $\mathrm{C}$ & AR88 adsorption \\
\hline$K_{1}$ & 1768 & 3231.2 & 2471.2 & \\
$K_{2}$ & 2495.2 & 2832 & 2515.6 & \\
$K_{3}$ & 3491.6 & 2656 & 2645.6 & \\
$K_{4}$ & 3534.4 & 2570.4 & 3657.2 & $\sum=11289.47$ \\
$k_{1}$ & 442 & 807.8 & 617.8 & $\sum / 16=705.59$ \\
$k_{2}$ & 623.8 & 708 & 628.9 & \\
$k_{3}$ & 872.9 & 664 & 661.4 & \\
$k_{4}$ & 883.6 & 642.6 & 914.3 & \\
$R$ & 441.6 & 165.2 & 296.5 & \\
\hline
\end{tabular}

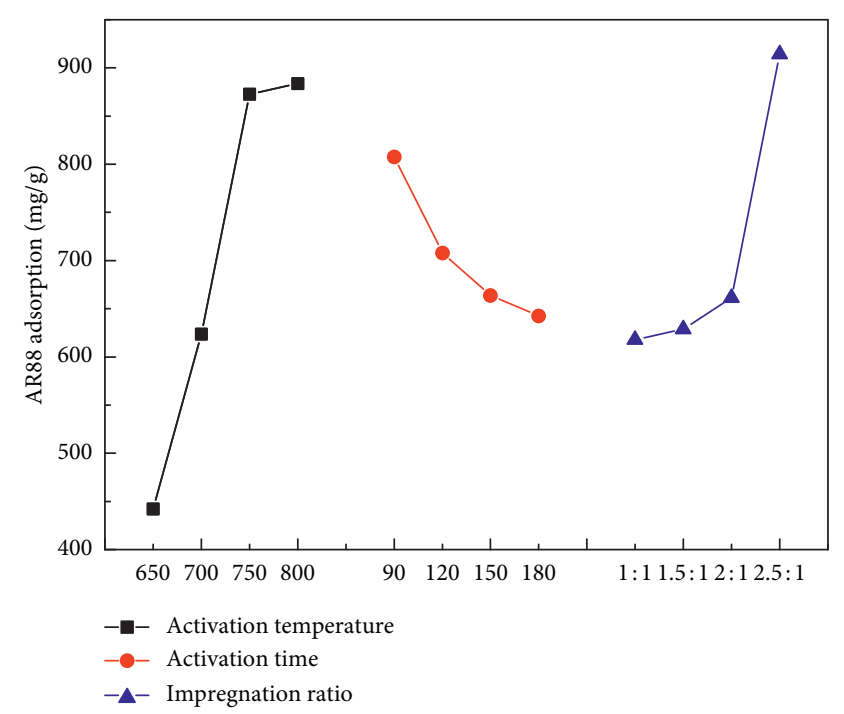

FIGURE 4: Effects of preparation conditions on AR88 adsorption of PPAC.

few wrinkles. Comparatively, Figure 5(c) shows PPAC had a rougher surface with developed pores. These pores might be created by that the organic matters were consumed by $\mathrm{KOH}$ and the thermal treatment, which suggested effective activation. 


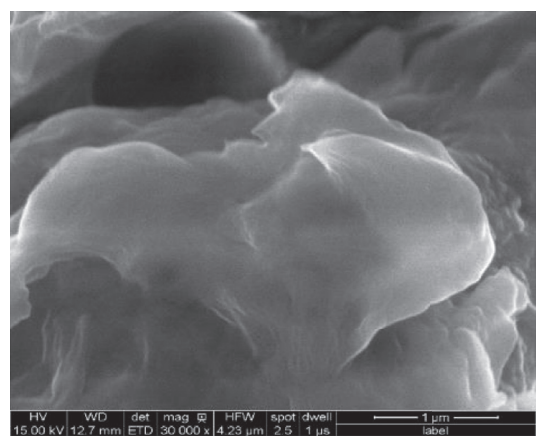

(a)

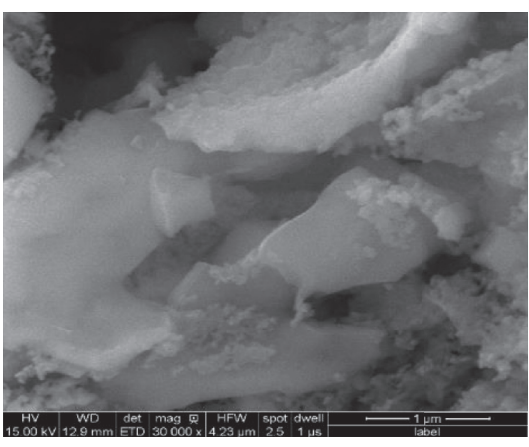

(b)

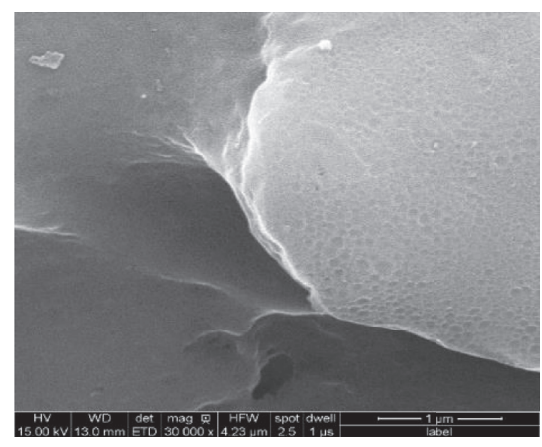

(c)

Figure 5: SEM images of (a) carbonized pomelo peel, (b) carbonized pomelo peel, and (c) PPAC.

Figure 6 shows the XRD patterns of PPAC. The results indicated that PPACs displayed two broad diffraction peaks at around $23.6^{\circ}$ and $43.5^{\circ}$, which were corresponding to the (002) and (100) planes of graphitic carbon structure, respectively. The two peaks became weaker at a higher activation temperature, suggesting the graphite crystallites were damaged by heat. PPAC had an amorphous structure.

The BET analysis results of PPAC $\left(\mathrm{A}_{4} \mathrm{~B}_{1} \mathrm{C}_{4}\right)$ are tabulated in Table 4. It showed that the BET specific area and the total pore volume of PPAC were $2504 \mathrm{~m}^{2} / \mathrm{g}$ and $1.185 \mathrm{~cm}^{3} / \mathrm{g}$, respectively. As for original pomelo peel, the BET specific area and the total pore volume were only $2.153 \mathrm{~m}^{2} / \mathrm{g}$ and $0.0019 \mathrm{~cm}^{3} / \mathrm{g}$, respectively, which were much lower than PPAC. It also presented the average pore diameter of PPAC was $1.017 \mathrm{~nm}$, which suggested that most of the pores were micropores. Thus, it indicated that PPAC might be an adsorbent with excellent performance.

3.3. Sorption Isotherms. To ulteriorly understand the mechanism of AR88 adsorption onto PPAC, the isothermal adsorption data were fitted by Langmuir, Freundlich, and Temkin isotherm models, as illustrated in Figure 7. Table 5 lists the corresponding parameters and the correlation coefficient $R^{2}$ figured out from the plottings. Higher $R^{2}$ showed that the Langmuir model fitted more closely to the isothermal sorption data than the Freundlich model and Temkin model. This suggested the surface of PPAC was compatible physically with monolayer adsorption, where strong interactions had occurred between the dyes molecules and carbons' surface [37].

The basic features of the Langmuir model could be explained by another equilibrium parameter $R_{L}$ [38], which is as follows:

$$
R_{L}=\frac{1}{1+C_{0} K_{L}},
$$

where $C_{0}(\mathrm{mg} / \mathrm{l})$ and $K_{L}(\mathrm{l} / \mathrm{mg})$ have been defined in equations (1) and (2). The value (0.0027-0.0081) of $R_{L}<1$ suggested that the adsorption of AR88 onto PPAC was a favorable process.

From Table 5, it also indicated that the theoretical maximal sorption value acquired from the Langmuir isotherm model was $1486 \mathrm{mg} / \mathrm{g}$. It was seen that PPAC could be

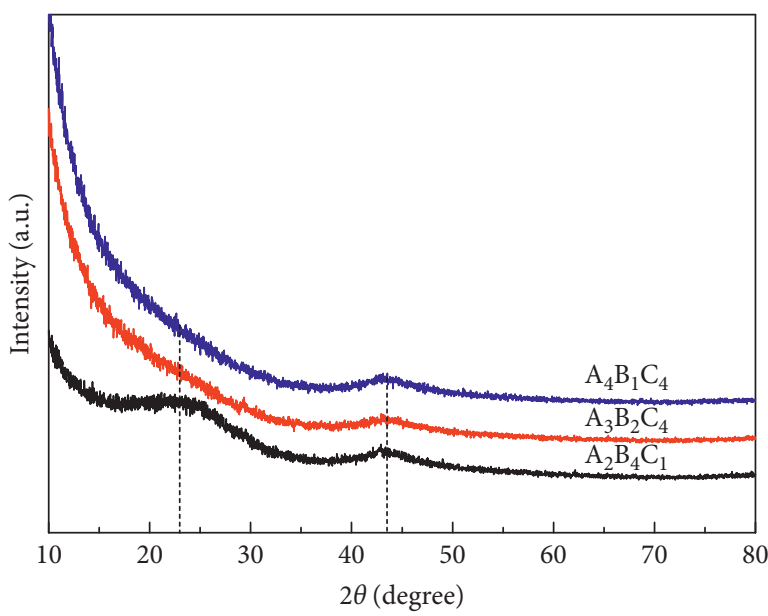

Figure 6: XRD patterns of PPAC.

TABLE 4: BET analysis results of PPAC.

\begin{tabular}{lccc}
\hline Sample & $S_{\mathrm{BET}}\left(\mathrm{m}^{2} / \mathrm{g}\right)$ & $\begin{array}{c}\text { Average pore width } \\
(\mathrm{nm})\end{array}$ & $V_{\text {total }}\left(\mathrm{cm}^{3} / \mathrm{g}\right)$ \\
\hline $\begin{array}{l}\text { PPAC } \\
\text { Pomelo } \\
\text { peel }\end{array}$ & 2504 & 1.017 & 1.185 \\
\hline
\end{tabular}

viewed as a suitable adsorbent for removing AR88. Furthermore, the Freundlich coefficient $n$ was $6.158(>1)$, suggesting favorable adsorption [39].

3.4. Adsorption Kinetics. Adsorption kinetics was applied for investigating the efficiency of adsorption at the solid-solution interface. Figure 8 presents that the sorption of AR8 8 onto PPAC demonstrated a rapid velocity at the beginning stage and $50 \%$ of the total adsorption occurred within $25 \mathrm{~min}$. This was probably because largest of adsorption active sites of PPAC were exposed to molecules of dye at the beginning. Figure 8 also presents that the adsorbed amount increased with increasing initial concentration of AR88. This was probably because a higher dye concentration provided more contact chances between molecules of dye and adsorption active sites. 


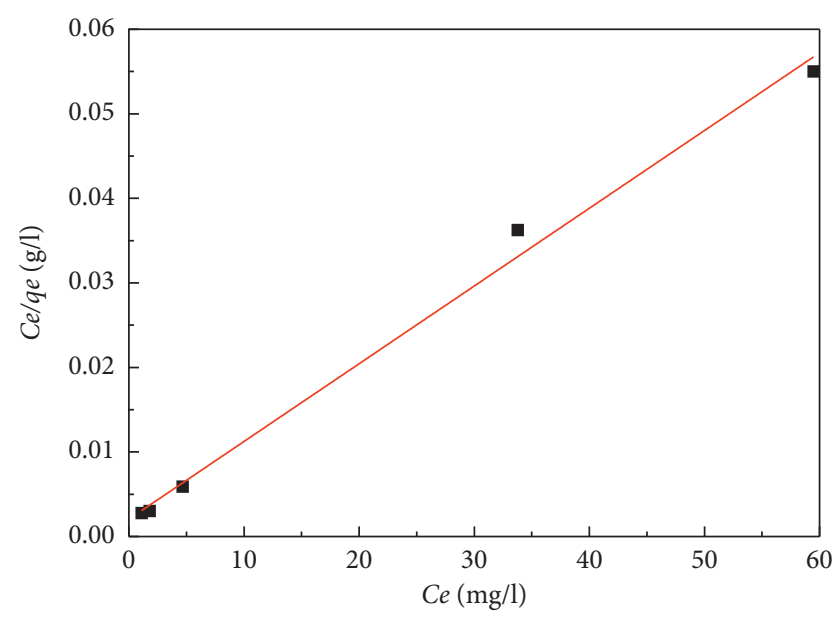

(a)

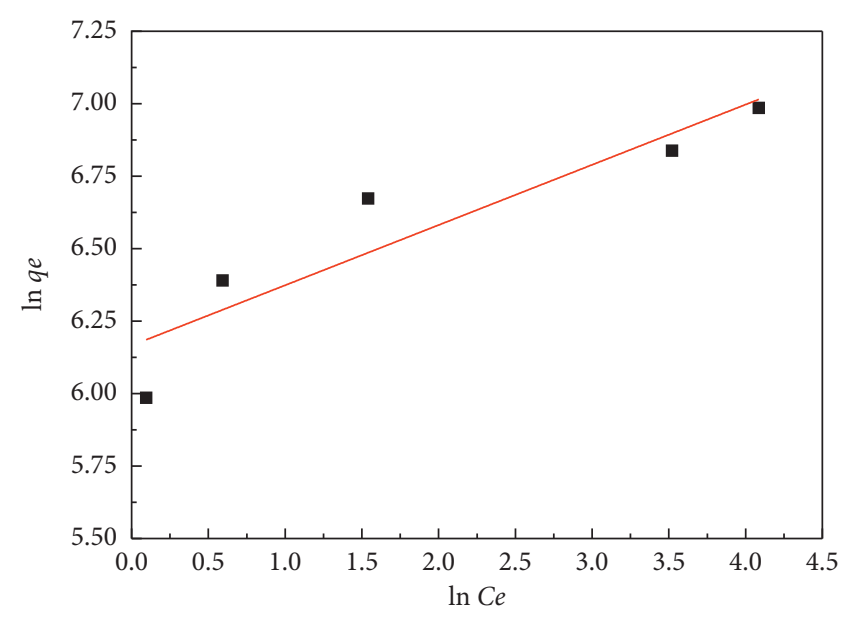

(b)

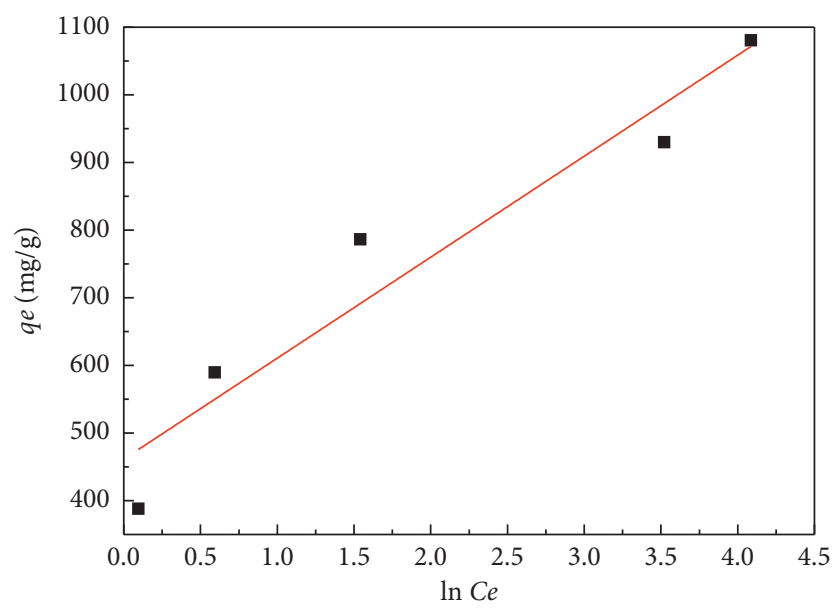

(c)

Figure 7: (a) Langmuir, (b) Freundlich, and (c) Temkin adsorption isotherms of PPAC.

TABLE 5: Adsorption isotherm parameters.

\begin{tabular}{ccccccccrcr}
\hline & \multicolumn{3}{c}{ Langmuir } & \multicolumn{3}{c}{ Freundlich } & \multicolumn{3}{c}{ Temkin } \\
$q_{m}$ & $K_{L}$ & $R^{2}$ & $R_{L}$ & $K_{F}$ & $n$ & $R^{2}$ & $B$ & $K_{T}$ \\
\hline 1486 & 0.6153 & 0.9996 & $0.0027-0.0081$ & 748.2 & 6.158 & 0.7750 & 166.1 & 95.50 & 0.8572 \\
\hline
\end{tabular}

The kinetics data were simulated with three models, which are shown in Figures 9(a)-9(c). Table 6 lists the kinetics parameters.

Clearly, the pseudo-second-order model fitted kinetics data better $\left(R^{2}>0.99\right)$ than the other two. Simultaneously, higher deviations between the experimental adsorption capacity $q_{e, \exp }$ and the theoretical value $q_{e, \text { cal }}$ were observed according to the pseudo-first-order model and intraparticle diffusion model. Thus, the pseudo-second-order model gave a better compliance with the kinetics data due to a much higher $R^{2}$ and lower deviations between $q_{e \text { exp }}$ and $q_{e, \text { cal }}$. This indicated that pseudosecond-order model was more valid to interpret the sorption kinetics. These results suggested that chemisorption seemed to be the rate-limiting step which was related to bond forces via electrons sharing or exchange between AR88 and PPAC [40].

Moreover, Table 6 shows the rate constant $k_{2}$ decreased as initial concentration of AR88 increased, which was probably because high concentrations generated intense competition for adsorption active sites, facilitating faster adsorption [41]. 


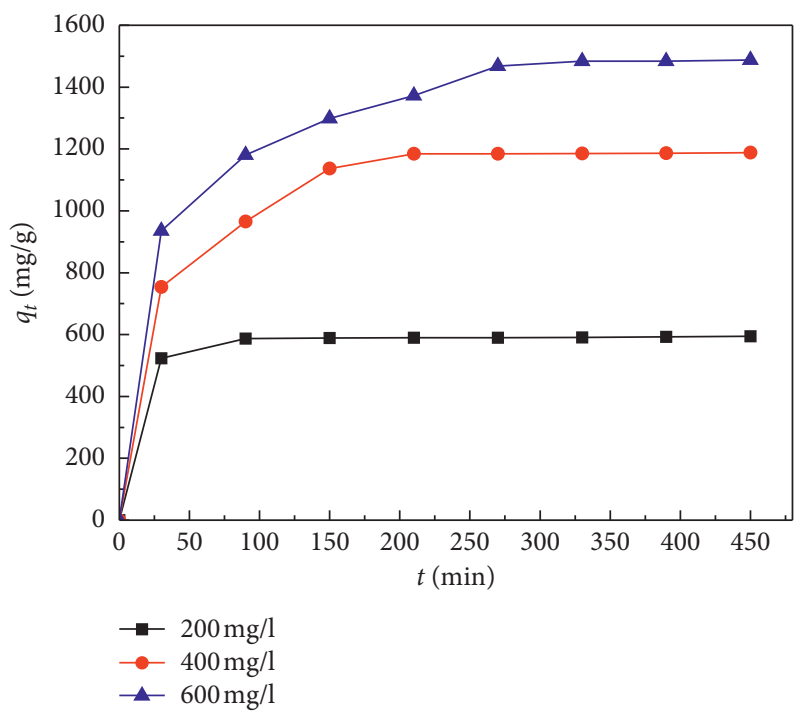

FIGURE 8: Effects of adsorption time on the adsorption of AR88 by PPAC.
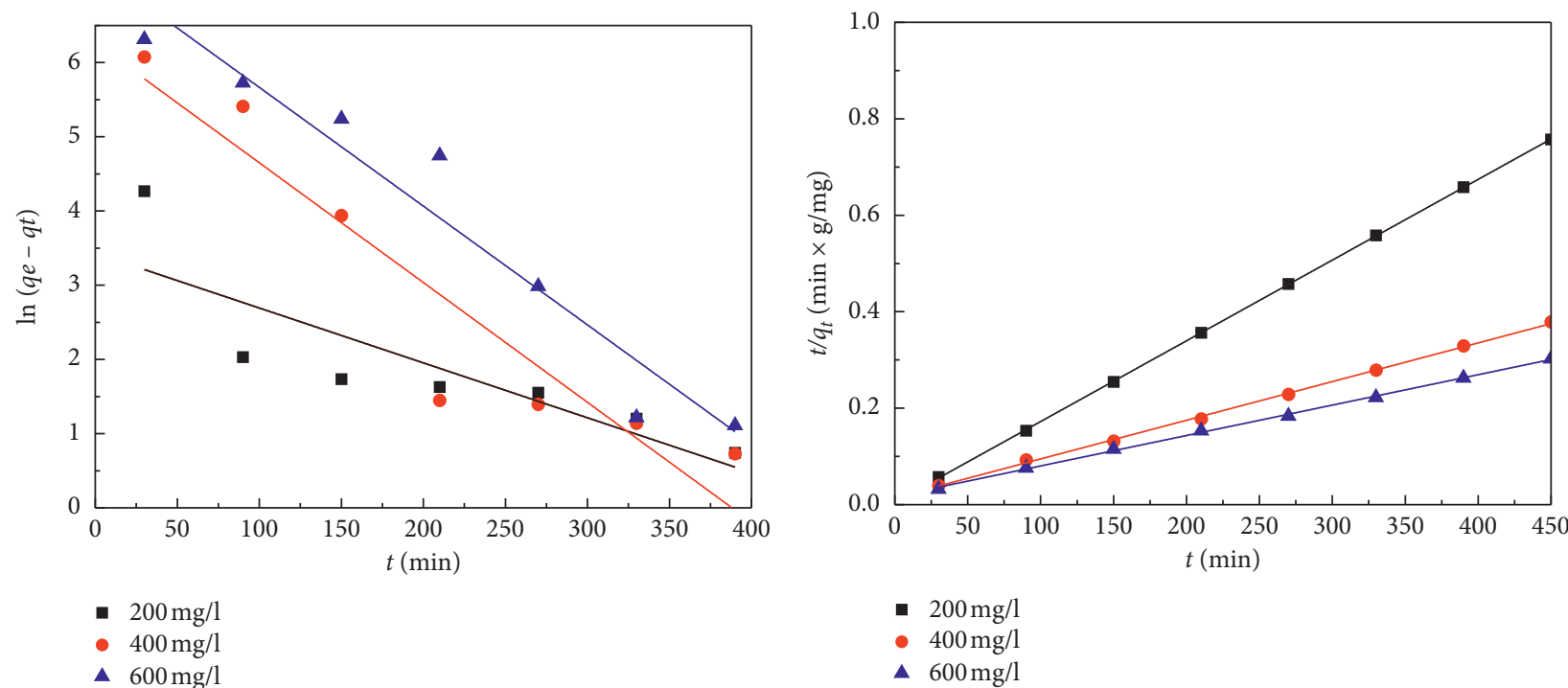

(a)

(b)

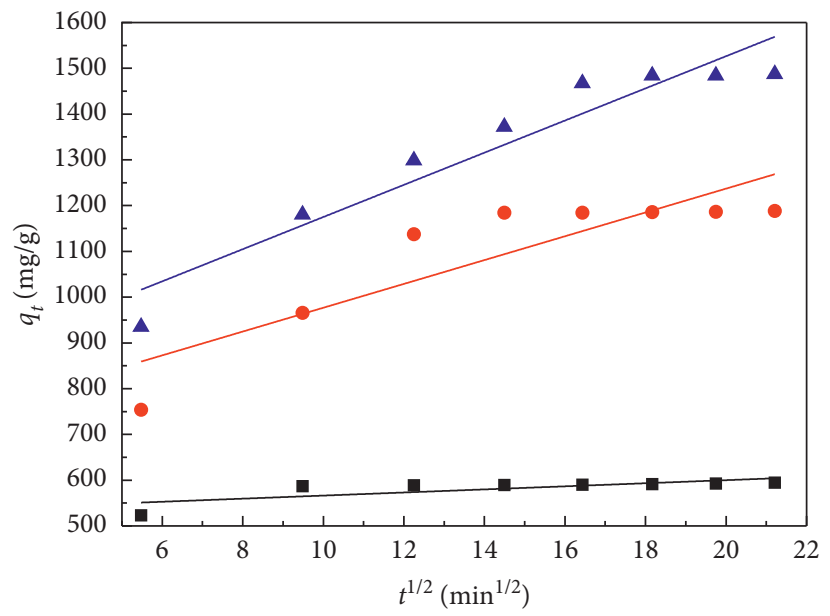

- $200 \mathrm{mg} / \mathrm{l}$

- $400 \mathrm{mg} / \mathrm{l}$

- $600 \mathrm{mg} / \mathrm{l}$

(c)

FIGURE 9: Adsorption kinetics of the AR88 adsorption by PPAC: (a) pseudo-first-order; (b) pseudo-second-order; (c) intraparticle diffusion. 
TABle 6: Adsorption kinetics parameters.

\begin{tabular}{|c|c|c|c|c|c|c|c|c|c|c|c|c|}
\hline \multirow[b]{2}{*}{$\mathrm{C}_{0}(\mathrm{mg} / \mathrm{l})$} & \multicolumn{4}{|c|}{ Pseudo-first-order model } & \multicolumn{4}{|c|}{ Pseudo-second-order model } & \multicolumn{4}{|c|}{ Intraparticle diffusion model } \\
\hline & $q_{e, \exp }(\mathrm{mg} / \mathrm{g})$ & $\begin{array}{c}q_{e, \mathrm{cal}} \\
(\mathrm{mg} / \mathrm{g})\end{array}$ & $\begin{array}{c}k_{1} \\
(1 / \mathrm{min})\end{array}$ & $R^{2}$ & $\begin{array}{c}q_{e, \exp } \\
(\mathrm{mg} / \mathrm{g})\end{array}$ & $\begin{array}{c}q_{e, \mathrm{cal}} \\
(\mathrm{mg} / \mathrm{g})\end{array}$ & $\begin{array}{c}k_{2} \\
(\mathrm{~g} / \mathrm{mg} \cdot \mathrm{min})\end{array}$ & $R^{2}$ & $\begin{array}{c}q_{e, \exp } \\
(\mathrm{mg} / \mathrm{g})\end{array}$ & $C(\mathrm{mg} / \mathrm{g})$ & $\begin{array}{c}k_{3} \\
\left(\mathrm{mg} / \mathrm{g} \cdot \min ^{1 / 2}\right)\end{array}$ & $R^{2}$ \\
\hline 200 & & & & & & & & & & & & \\
\hline 400 & & & & & & & & & & & & \\
\hline 600 & 1487.40 & 1430.82 & 0.0160 & 0.9389 & 1487.40 & 1586.29 & 0.000023 & 0.9988 & 1487.40 & 823.72 & 35.135 & 0.9142 \\
\hline
\end{tabular}

\section{Conclusions}

In this study, the pomelo peel was selected as a precursor to prepare activated carbon (PPAC) by using carbonization and $\mathrm{KOH}$ activation. As a cheap adsorbent, PPAC was used to remove AR88 dyes from water. The characterization results showed PPAC had a microporous and amorphous carbon structure. The BET specific area and the total pore volume of optimal PPAC were $2504 \mathrm{~m}^{2} / \mathrm{g}$ and $1.185 \mathrm{~cm}^{3} / \mathrm{g}$, respectively. According to orthogonal experiments, the preparation parameter that mattered the most to AR88 removal efficiency was the activation temperature of PPAC, followed by impregnation ratio and activation time. The optimal preparation conditions of PPAC were at activation temperature $800^{\circ} \mathrm{C}$, activation time $90 \mathrm{~min}$, and impregnation ratio $2.5: 1$. Langmuir model fitted more closely to the isothermal sorption data than the Freundlich model and Temkin model. The theoretical maximal sorption value acquired from the Langmuir isotherm model was $1486 \mathrm{mg} / \mathrm{g}$. The pseudo-second-order model was more valid to interpret the sorption process, which suggested that chemisorption seemed to be the rate-limiting step.

\section{Data Availability}

The data are available from the corresponding author upon request.

\section{Conflicts of Interest}

The authors declare that there are no conflicts of interest.

\section{Acknowledgments}

This work was supported by the Research Climbing Program of Xiamen University of Technology (XPDKQ19015 and XPDKT20015) and the Education Department of Fujian Province (JAT200473).

\section{References}

[1] G. K. Sarma, S. Sen Gupta, and K. G. Bhattacharyya, "Removal of hazardous basic dyes from aqueous solution by adsorption onto kaolinite and acid-treated kaolinite: kinetics, isotherm and mechanistic study," SN Applied Sciences, vol. 1, no. 3, p. 211, 2019.

[2] A. A. Essawy, A. E. H. Ali, and M. S. A. Abdel-Mottaleb, "Application of novel copolymer- $\mathrm{TiO}_{2}$ membranes for some textile dyes adsorptive removal from aqueous solution and photocatalytic decolorization," Journal of Hazardous Materials, vol. 157, no. 2-3, pp. 547-552, 2008.
[3] F. Mashkoor and N. Abu, "Magsorbents: potential candidates in wastewater treatment technology-a review on the removal of methylene blue dye," Journal of Magnetism and Magnetic Materials, vol. 500, 2020.

[4] S. Khamparia and D. Jaspal, "Investigation of adsorption of Rhodamine B onto a natural adsorbent Argemone mexicana," Journal of Environmental Management, vol. 183, pp. 786-793, 2016.

[5] M. Vakili, M. Rafatullah, B. Salamatinia, M. H. Ibrahim, and A. Z. Abdullah, "Elimination of reactive blue 4 from aqueous solutions using 3-aminopropyl triethoxysilane modified chitosan beads," Carbohydrate Polymers, vol. 132, pp. 89-96, 2015.

[6] P. O. Bankole, A. A. Adekunle, and S. P. Govindwar, "Enhanced decolorization and biodegradation of acid red 88 dye by newly isolated fungus, Achaetomium strumarium," Journal of Environmental Chemical Engineering, vol. 6, no. 2, pp. 1589-1600, 2018.

[7] B. Zhao, Z. Zhu, X. D. Qin, Z. Li, and H. Zhang, "Highly efficient and stable CuZr-based metallic glassy catalysts for azo dye degradation," Journal of Materials Science \& Technology, vol. 46, pp. 88-97, 2020.

[8] L. Mais, A. Vacca, M. Mascia, E. M. Usai, S. Tronci, and S. Palmas, "Experimental study on the optimisation of azodyes removal by photo-electrochemical oxidation with $\mathrm{TiO} 2$ nanotubes," Chemosphere, vol. 248, Article ID 125938, 2020.

[9] I. H. Alsohaimi, A. M. Nassar, T. A. Seaf Elnasr, and B. a. Cheba, "A novel composite silver nanoparticles loaded calcium oxide stemming from egg shell recycling: a potent photocatalytic and antibacterial activities," Journal of Cleaner Production, vol. 248, Article ID 119274, 2020.

[10] N. Askari, M. Farhadian, A. Razmjou, and H. Hashtroodi, "Nanofiltration performance in the removal of dye from binary mixtures containing anthraquinone dyes," Desalination and Water Treatment, vol. 57, no. 39, pp. 18194-18201, 2016.

[11] S. Raghu and C. Ahmed Basha, "Chemical or electrochemical techniques, followed by ion exchange, for recycle of textile dye wastewater," Journal of Hazardous Materials, vol. 149, no. 2, pp. 324-330, 2007.

[12] N. Oturan, M. Zhou, and M. A. Oturan, "Metomyl degradation by electro-fenton and electro-fenton-like processes: a kinetics study of the effect of the nature and concentration of some transition metal ions as catalyst," The Journal of Physical Chemistry A, vol. 114, no. 39, pp. 10605-10611, 2010.

[13] L. Fan, Y. Zhou, W. Yang, G. Chen, and F. Yang, "Electrochemical degradation of aqueous solution of Amaranth azo dye on ACF under potentiostatic model," Dyes and Pigments, vol. 76, no. 2, pp. 440-446, 2008.

[14] M. S. Khehra, H. S. Saini, D. K. Sharma, B. S. Chadha, and S. S. Chimni, "Biodegradation of azo dye C.I. Acid Red 88 by an anoxic-aerobic sequential bioreactor," Dyes and Pigments, vol. 70, no. 1, pp. 1-7, 2006.

[15] A. A. Bhatti, M. Oguz, and M. Yilmaz, "Magnetizing calixarene: magnetizing calixarene: azo dye removal from aqueous media by $\mathrm{Fe} 3 \mathrm{O} 4 \mathrm{Nanoparticles} \mathrm{fabricated} \mathrm{with} \mathrm{carboxylic-}$ 
substituted calix[4]arene," Journal of Chemical \& Engineering Data, vol. 62, no. 9, pp. 2819-2825, 2017.

[16] A. M. Nassar, A. M. Elseman, I. H. Alsohaimi, N. F. Alotaibi, and A. Khan, "Diaqua oxalato strontium(II) complex as a precursor for facile fabrication of Ag-NPs@SrCO3, characterization, optical properties, morphological studies and adsorption efficiency," Journal of Coordination Chemistry, vol. 72, no. 5-7, pp. 771-785, 2019.

[17] M. Rafatullah, O. Sulaiman, R. Hashim, and A. Ahmad, "Adsorption of methylene blue on low-cost adsorbents: a review," Journal of Hazardous Materials, vol. 177, no. 1-3, pp. 70-80, 2010.

[18] W. Zhang, L. Y. Zhang, X. J. Zhao, and Z. Zhou, "Citrus pectin derived porous carbons as a superior adsorbent toward removal of methylene blue," Journal of Solid State Chemistry, vol. 243, pp. 101-105, 2016.

[19] A. K. Prajapati and M. K. Mondal, "Comprehensive kinetic and mass transfer modeling for methylene blue dye adsorption onto $\mathrm{CuO}$ nanoparticles loaded on nanoporous activated carbon prepared from waste coconut shell," Journal of Molecular Liquids, vol. 307, Article ID 112949, 2020.

[20] J. V. Freitas, F. G. E. Nogueira, and C. S. Farinas, "Coconut shell activated carbon as an alternative adsorbent of inhibitors from lignocellulosic biomass pretreatment," Industrial Crops and Products, vol. 137, pp. 16-23, 2019.

[21] P. N. Y. Yek, R. K. Liew, M. S. Osman et al., "Microwave steam activation, an innovative pyrolysis approach to convert waste palm shell into highly microporous activated carbon," Journal of Environmental Management, vol. 236, pp. 245-253, 2019.

[22] J. A. Kumar, D. J. Amarnath, S. Sathish et al., "Enhanced PAHs removal using pyrolysis-assisted potassium hydroxide induced palm shell activated carbon: batch and column investigation," Journal of Molecular Liquids, vol. 279, pp. 77-87, 2019.

[23] E. Menya, P. W. Olupot, H. Storz, M. Lubwama, and Y. Kiros, "Characterization and alkaline pretreatment of rice husk varieties in Uganda for potential utilization as precursors in the production of activated carbon and other value-added products," Waste Management, vol. 81, pp. 104-116, 2018.

[24] Y. Shen, N. Zhang, and Y. Fu, "Synthesis of high-performance hierarchically porous carbons from rice husk for sorption of phenol in the gas phase," Journal of Environmental Management, vol. 241, pp. 53-58, 2019.

[25] M. Ziati and S. Hazourli, "Experimental investigation of activated carbon prepared from date stones adsorbent electrode for electrosorption of lead from aqueous solution," Microchemical Journal, vol. 146, pp. 164-169, 2019.

[26] T. M. Darweesh and M. J. Ahmed, "Batch and fixed bed adsorption of levofloxacin on granular activated carbon from date ( Phoenix dactylifera L.) stones by $\mathrm{KOH}$ chemical activation," Environmental Toxicology and Pharmacology, vol. 50, pp. 159-166, 2017.

[27] Z. Li, H. Hanafy, L. Zhang et al., "Adsorption of congo red and methylene blue dyes on an ashitaba waste and a walnut shellbased activated carbon from aqueous solutions: experiments, characterization and physical interpretations," Chemical Engineering Journal, vol. 388, Article ID 124263, 2020.

[28] S. Teixeira, C. Delerue-Matos, and L. Santos, "Application of experimental design methodology to optimize antibiotics removal by walnut shell based activated carbon," Science of the Total Environment, vol. 646, pp. 168-176, 2019.

[29] Q. Wang, C. Zhou, Y.-j. Kuang, Z.-h. Jiang, and M. Yang, "Removal of hexavalent chromium in aquatic solutions by pomelo peel," Water Science and Engineering, vol. 13, no. 1, pp. 65-73, 2020.

[30] D. Cheng, H. H. Ngo, W. Guo et al., "Feasibility study on a new pomelo peel derived biochar for tetracycline antibiotics removal in swine wastewater," Science of the Total Environment, vol. 720, Article ID 137662, 2020.

[31] D. Cheng, H. H. Ngo, W. Guo et al., "Improving sulfonamide antibiotics removal from swine wastewater by supplying a new pomelo peel derived biochar in an anaerobic membrane bioreactor," Bioresource Technology, vol. 319, Article ID 124160, 2021

[32] L. Zhu, Y. Wang, Y. Wang, L. You, X. Shen, and S. Li, “An environmentally friendly carbon aerogels derived from waste pomelo peels for the removal of organic pollutants/oils," Microporous and Mesoporous Materials, vol. 241, pp. 285-292, 2017.

[33] J. Zou, X. Liu, W. Chai et al., "Sorption of oil from simulated seawater by fatty acid-modified pomelo peel," Desalination and Water Treatment, vol. 56, no. 4, pp. 939-946, 2015.

[34] A. Gundogdu, C. Duran, H. B. Senturk et al., "Adsorption of phenol from aqueous solution on a low-cost activated carbon produced from tea industry waste: equilibrium, kinetic, and thermodynamic study," Journal of Chemical \& Engineering Data, vol. 57, no. 10, pp. 2733-2743, 2012.

[35] S. Lv, C. Li, J. Mi, and H. Meng, "A functional activated carbon for efficient adsorption of phenol derived from pyrolysis of rice husk, $\mathrm{KOH}$-activation and EDTA-4Na-modification," Applied Surface Science, vol. 510, Article ID 145425, 2020.

[36] S. K. Theydan and M. J. Ahmed, "Optimization of preparation conditions for activated carbons from date stones using response surface methodology," Powder Technology, vol. 224, pp. 101-108, 2012.

[37] H. Liu, X. Wang, G. Zhai et al., "Preparation of activated carbon from lotus stalks with the mixture of phosphoric acid and pentaerythritol impregnation and its application for $\mathrm{Ni}(\mathrm{II})$ sorption," Chemical Engineering Journal, vol. 209, pp. 155-162, 2012

[38] X. Z. Chu, Y. J. Zhao, Y. H. Kan et al., "Dynamic experiments and model of hydrogen and deuterium separation with micropore molecular sieve $\mathrm{Y}$ at $77 \mathrm{~K}$," Chemical Engineering Journal, vol. 152, no. 2-3, pp. 428-433, 2009.

[39] S. K. Sharma and R. Sanghi, Wastewater Reuse and Management, Springer, Netherlands, 2013, https://www.springer. com/gp/book/9789400749412.

[40] Y. S. Ho and G. McKay, "Pseudo-second order model for sorption processes," Process Biochemistry, vol. 34, no. 5, pp. 451-465, 1999.

[41] A. F. Abbas and M. J. Ahmed, "Mesoporous activated carbon from date stones (Phoenix dactylifera L.) by one-step microwave assisted $\mathrm{K}_{2} \mathrm{CO}_{3}$ pyrolysis," Journal of Water Process Engineering, vol. 9, pp. 201-207, 2016. 